\title{
Analyzing the bearing capacity of materials used in arresting systems as a suitable risk mitigation strategy for runway excursions in landlocked aerodromes
}

\author{
M. Ketabdari, E. Toraldo \& M. Crispino \\ Transportation Infrastructures and Geosciences section, Department of Civil and Environmental Engineering, \\ Politecnico di Milano University, Milan, Italy
}

\begin{abstract}
Runway-related incidents/accidents based on aircraft operations can be categorized as incursions and excursions. Among all excursion events, landing and take-off overruns are responsible for the major portions. In fact, safety efforts are persistently needed by discovering these types of events, assessing the consequent risks and developing befitting mitigation strategies. There are numerous mitigation strategies to reduce the severity of consequences of runway overrun events. One of the most common strategies is to expand the geometry of the Runway End Safety Area (RESA), which is effective but beside the fact that it is noticeably expensive, many airports are landlocked, and it is difficult to expand their lands. On the other hand, Engineered Materials Arresting Systems (EMAS), as precast blocks or cast in situ slabs, are emerging as a possible interesting solution. Although this is not a new-discovered solution, many aspects are still unknown and are needed to be studied. Therefore, this paper reports the achievements of a study in which a numerical code was developed to simulate the behavior of EMAS materials and evaluate their bearing capacity and efficiency in reducing the aircraft braking distance in case of runway overrun. Thanks to this numerical code, it is possible to achieve not only the exact aircraft stopping location, but also the critical drag and uplift forces acting on the aircraft main gear and the deceleration rate (tire-material interface) after striking the arresting blocks. Additional outcome is a risk contour map overlapped on the EMAS layout that assigns the probability of aircraft stoppage location to the related coordinates on the arrestor bed. In order to discover an appropriate EMAS material with enough bearing capacity, low-density concrete with different natural, mineral and synthetic additives were considered in the evaluations. Boeing B747-8 aircraft was selected as the case study in all the computations.
\end{abstract}

Keywords: Material bearing capacity, arresting systems, mitigation strategy, aerodrome risk analyses, runway end safety area

\section{INTRODUCTION}

Aircraft ground operation events assigned to the runway are classified according to their location of occurrence. They can be divided into incursion and excursion events. Runway overruns (in particular, those that occur during landing) are responsible for the major portion of runway excursion events (Ketabdari et al., 2020). Numerous boundary conditions can convert a normal landing operation into an overrun event (e.g. poor aircraft braking potential conditions due to its low maintenance level, unfavorable weather conditions and pilot errors). 
In order to mitigate the severity of consequences of runway overrun incidents/accidents and to protect involved passengers, specific areas after runway end borders are designed which are called Runway End Safety Areas (RESAs) (EASA, 2014). RESA must be capable of supporting the aircraft in occasional overruns, in dry pavement condition, without causing aircraft structural damage or injury to its occupants (Crispino et al., 2018). International Civil Aviation Organization (ICAO) recommended to increase the length of standard RESA from $90 \mathrm{~m}$ to $240 \mathrm{~m}$, starting from the end of the runway strip (which itself is $60 \mathrm{~m}$ from the end of the runway) (ICAO, 2010). This new dimension is recommended for designing new runways and the existing ones. Although this strategy may mitigate the severity of incidents/accidents, not all the airports have enough land to accommodate these standard recommendations (Ketabdari et al., 2018).

Engineered Materials Arresting System (EMAS), which is approved by Federal Aviation Administration (FAA) (FAA, 2004, FAA, 2005), is an alternative mitigation strategy for the consequences of landing overrun events for those airports with landlocked circumstances. Therefore, there is no necessity to resize the length of a runway or declare its length to be less than the actual length if there is an adverse operational influence on the airport.

EMAS is defined as a bed of pre-cast blocks, consisting of FAA-approved materials, that is placed at the area after runway end threshold to decelerate an overrunning aircraft in an emergency. No external energy source is required for this system since it is a passive mitigation action. These blocks will predictably crush under the weight of an aircraft to provide one gentle aircraft deceleration. Drag forces develop at the tire-arrestor material interface to decelerate the aircraft. The successful deceleration reduces stopping distance considerably. An EMAS is positioned within the RESA set back area that is located after the runway end border and this setback length protects the arrestor bed from the aircraft intrusion during an under shoot, a short overrun, or material degradation due to jet blast.

In 1985, soft ground arrestor materials (such as clay, sand and water ponds) were considered in designing an arresting bed in order to evaluate their capability in stopping the aircraft in the shortest distance. Investigation was carried out for these materials at their best performance conditions to determine their functionality. The arresting bed simulations indicated that in clay and sand, the stopping distance would be $198 \mathrm{~m}(650 \mathrm{ft}$.) and $183 \mathrm{~m}$ (600ft.) respectively. For water ponds, aircraft deceleration would not be neither constant nor gentle, therefore the damages to the aircraft would be more severe. In any case, due to the limitations due to the characteristics of these materials, they were discarded (Cook, 1987).

In 1986, the ARRESTOR computer code was used by FAA to predict aircraft stopping distances after entering RESA (Heymsfield, 2009). This code is an extension of the FITER 1 which was developed in 1985 by Cook (Cook, 1985) to predict fighter plane movements on soft ground. The Arrestor code uses EMAS geometry and material properties, and limited aircraft characteristics. This code could analyze the behavior of arrestor for only three types of aircraft - Boeing 707, 727 and 747. In order to evaluate other types of aircraft, a new computer code, SGAS (Soft Ground Arresting System) was developed in 1987 (Cook, 1987). Though it did not have user friendly pop-up windows, it required the input of only those aircraft parameters which are involved during the tire-material interaction. The outputs of these programs are the stopping distance, deceleration pattern, gear loads, tire penetration and the EMAS deformation. The sensitivity analysis with the aircraft type showed that the stopping distance increases for the heavier aircraft. The stopping distance increases as the material strength is increased and for a higher bed depth configuration, the aircraft decelerates faster because of the increase in the drag force.

In 2013, four different types of aircraft (B737-900ER, B767-400ER, B757-300, B747$400 E R$ ) were investigated. The SGAS that was used for the computations of these aircraft categories, was not included in the FAA arrestor code. Furthermore, sensitivity analysis was carried out considering different EMAS configurations and compressive strength of the material (Heymsfield, 2013). Typically, an EMAS is designed for the most critical (i.e. heaviest) aircraft operating at the airport. In 2016, lightweight regional jets have been investigated (Heymsfield, 2016). Aircraft behavior after entering an installed EMAS at the RESA for CRJ200ER, B727100 , and B737-900ER aircraft have been studied. 
The scope of this study is to evaluate the functionality of EMAS in mitigating the consequences of landing overruns with the principal aim of safety for the passengers on board. The basic concepts for modelling the aircraft tire-arrestor material interface within the EMAS, are developed based on the previous studies in this field (Heymsfield, 2009).

\section{METHODOLOGY: MAIN GEAR FOOTPRINT WITHIN AN EMAS}

Aircraft behavior within the EMAS area can be simulated respect to the aircraft braking distance. In other words, in case of landing overrun, the distance from the runway end threshold at which the aircraft decelerates to a full stop within the EMAS installation (Ketabdari et al., 2019). To compute arresting distance, it is necessary to the correct EMAS entry velocity should be selected based on system design requirements laid down by the FAA. Since the entity of the desired output is based on Probabilistic Risk Analysis (PRA), aircraft touchdown velocity and EMAS entry velocity are both selected as normal Probability Density Functions (PDFs).

In order to simulate the behavior of aircraft within EMAS installation, footprint of aircraft main gear and its interaction with EMAS material after entry should be analyzed. Tirematerial interface model is required to couple the forces generated as the result of smashing arresting materials under aircraft landing gear. Consequently, deceleration rate, drag and vertical forces and ultimately stopping distance can be obtained. The drag and the vertical forces are functions of material mass density, crushing stress, EMAS entry velocity, and tire footprint area. In this regard, it is necessary to consider that tire deformation has dynamic characteristic (Pasindu et al., 2011) and it changes according to the velocity of the aircraft that leads to variation in tire footprint, as presented in Figure 1.

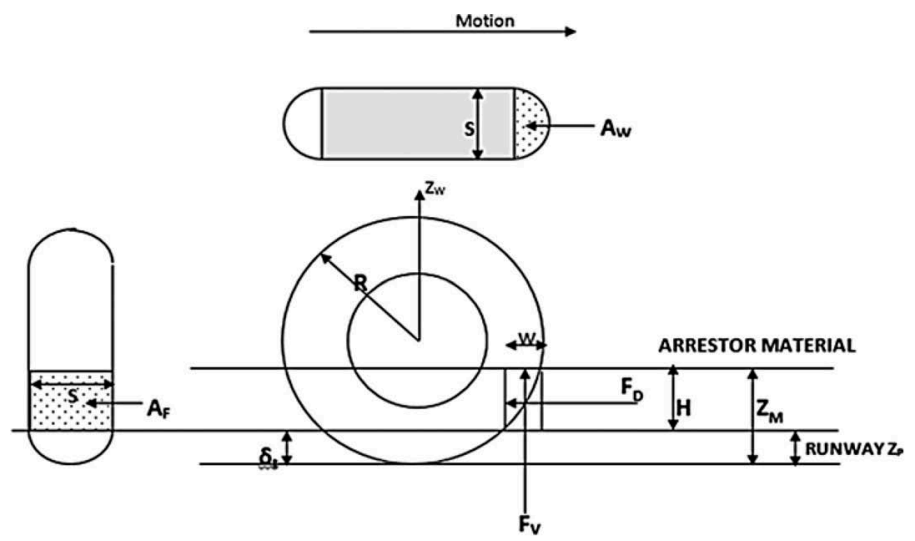

Figure 1. Wheel interface model to define drag and vertical forces (Cook, 1987).

As an aircraft enters an arresting bed, material crushes under the aircraft's self-weight and creates an interface between the tire and arresting material. The forces that are generated at the interface are vertical force, which supports the aircraft weight, and drag force, which aids in aircraft deceleration. Vertical and the drag forces are equal to the pressures on the horizontal $\left(\mathrm{A}_{\mathrm{W}}\right)$ and vertical tire footprints $\left(\mathrm{A}_{\mathrm{F}}\right)$, as shown in Figure 1. For this matter, a conceptual model (Cook, 1987) is implemented to involve these forces into principal equilibrium of deceleration rate and consequent arresting distance simulations, as explained in the following. 


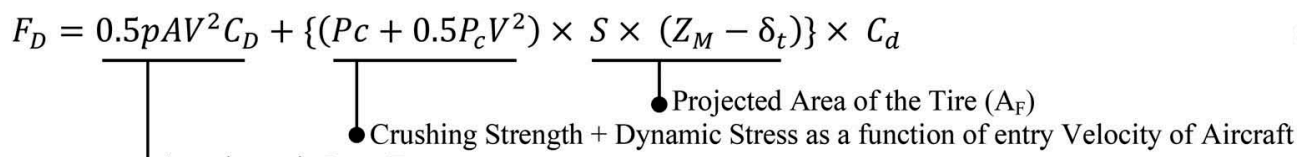

$$
\begin{aligned}
& F_{V}=0.5 p A V^{2} C_{L}+\left\{\left(P_{c}+0.5 P_{c} V^{2}\right) \times S \times W \times 0.66\right\} \times C_{L}+K \times \delta_{t} \\
& \int_{\text {Crushing Strength }+ \text { Dynamic Stress as a function of entry Velocity of Aircraft }}
\end{aligned}
$$

$$
W=R^{2}-\left(R-Z_{m}+\delta_{t}\right)^{2}-R^{2}-\left(R-\delta_{t}\right)^{2}
$$

Where, $A$ is the aircraft wing area $\left[\mathrm{m}^{2}\right] ; V$ is aircraft cruise speed $[\mathrm{m} / \mathrm{s}] ; R$ is landing main gear radius [m]; $S$ is tire width [m]; $\delta_{t}$ is the tire deformation; $\rho$ is the air density $\left[\mathrm{kg} / \mathrm{m}^{3}\right] ; C_{D}$ is the coefficient of drag; $C_{L}$ is the coefficient of lift for the concerned aircraft; $\mathrm{C}_{\mathrm{d}}$ is coefficient of drag at zero lift, which for light aircraft can be from 0.02 to 0.04 and for subsonic aircraft can be from 0.013 to $0.020 ; Z_{m}$ is EMAS thickness [m]; $K$ is half the tire stiffness; $P_{c}$ is the material crushing stress $[\mathrm{Pa}] ; F_{D}$ is the generated drag force; $F_{V}$ is the generated vertical force; $W$ is the main gear footprint after entering the EMAS area (Cook, 1987).

By adopting above equations, an incremental distance and a new reduced speed due to deceleration is computed at every step which becomes the initial conditions for the computations in the next step. The distances are added cumulatively to get the final arresting distance when the aircraft comes to a full stop. Consequently, the computation continues till the aircraft velocity reaches a zero at final stage.

\section{DEVELOPMENT OF A MATLAB APPLICATION}

The model described in the previous paragraphs has been implemented in MATrix LABoratory (MATLAB $B)$ in order to compute the stopping distance of the aircraft within different EMAS materials. The developed application named ABIAS (Aircraft Behavior in Arresting System) can be used for any airport with any type of land restrictions.

The aircraft characteristics can be numerically inputted, and runway geometry can be reported in coordinates in the referring mesh calculation, pointing the threshold at which the runway ends and EMAS installation starts. The application then simulates the aircraft behavior inside the EMAS by means of the following inputs: Maximum Take-Off Weight (MTOW), average wingspan, main gear load, mean touchdown velocity, headwind/tailwind velocities, runway length, EMAS dimensions, material with desired crushing stress $(\mathrm{Pc})$ to be used in EMAS, etc. The outputs are aircraft full-stop PDF with/without EMAS installation in case of landing overrun, aircraft braking distance contour map overlapped on EMAS layout.

General Aviation with MTOW less than $5.7 \mathrm{t}$ will normally stop within the runway without entering EMAS installation, therefore, mainly commercial aircraft (with MTOW $\geq 5.7 \mathrm{t}$ ) are considered in order to develop ABIAS application. More assumptions that are adopted in development of this application are as following:

- reverse thrust is not being considered as the aircraft exits the runway;

- aircraft braking system is in well-maintenance condition;

- there is no aircraft braking or use of reverse thrust once an aircraft enters the EMAS area.

Finally, it should be noted that ABIAS application, developed by the authors, is compatible with multiple wheels and dual-gear aircraft. 
Boeing 747-8 is selected to be studied by ABIAS, since B747-8 is amongst top five heaviest commercial aircraft with MTOW equal to $450 \mathrm{t}$ and wingspan of $68.4 \mathrm{~m}$. Therefore, analyzing this case study will lead to considering longest braking distance in case of landing overrun accident. The simulation is performed with a typical runway with an average length of 2200 meters, EMAS length equal to $150 \mathrm{~m}$ with $0.3 \mathrm{~m}$ thickness. The selected material of the EMAS is Low-Density Concrete (LDC) containing natural additives with crushing (threshold) stress $\mathrm{Pc}, 930 \mathrm{kPa}$. Pc is the ultimate stress at which the highest strains are produced and after which greater stresses are required to increase the marginal strains.

The probability distributions of aircraft full stop have been calculated for with and without EMAS installation in order to verify and demonstrate the functionality of arresting materials in decreasing the aircraft braking distance in case of landing overrun, as presented in Figure 2.
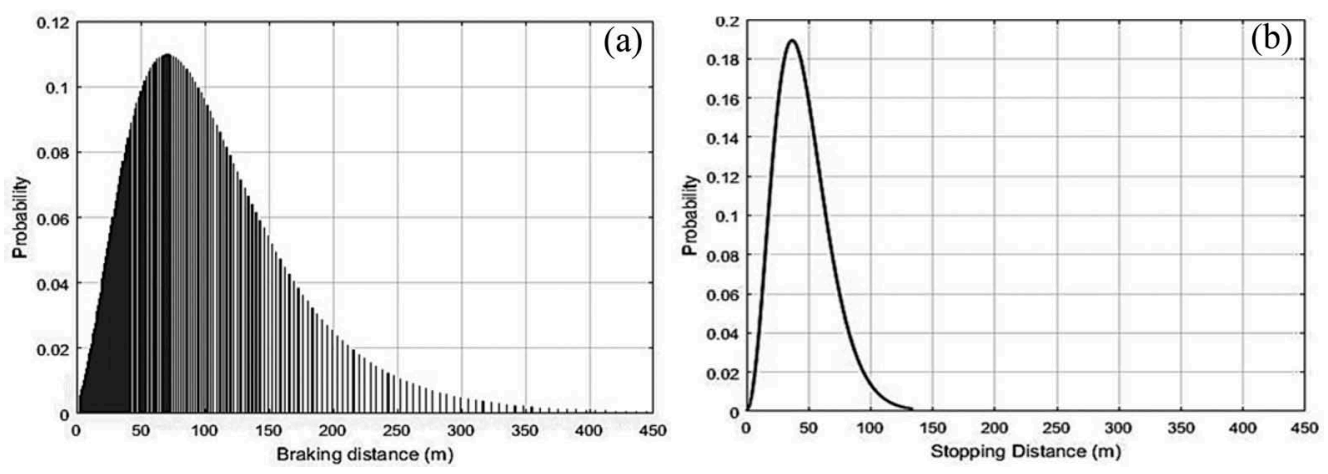

Figure 2. Primary output; Aircraft arresting distance PDF of B747-8 in case of landing overrun, (a) for paved RESA, (b) for RESA enhanced with EMAS.

Figure 2 is demonstrating the behaviour of aircraft in case of landing overrun after passing the runway end threshold with and without presence of EMAS. According to graph (a) of Figure 2, the tail of arresting distance PDF (extreme rare scenarios) indicates that, B747-8 aircraft can reach to the full stop up to $450 \mathrm{~m}$ after runway end, with the median of $75 \mathrm{~m}$ within the paved RESA. On the other hand, as presented in graph (b), by enhancing the RESA by EMAS installation, the peak of the calculated braking distance PDF is around $45 \mathrm{~m}$ after EMAS starting origin and the tail of this PDF demonstrates that the aircraft will reach to the full stop before $135 \mathrm{~m}$ from the EMAS origin.

Cumulative arresting distance PDF for B747-8 aircraft have been calculated in second step for similar conditions, as presented in Figure 3. By comparing graph (a) and graph (b) of Figure 3, it can be observed that in presence of EMAS, the arresting distance probability accumulates faster up to $75 \mathrm{~m}$ from the EMAS entry and then changes slightly till the full arresting distance. These PDFs are implemented in developing the final probability contour intervals overlapped on under study EMAS layout. 

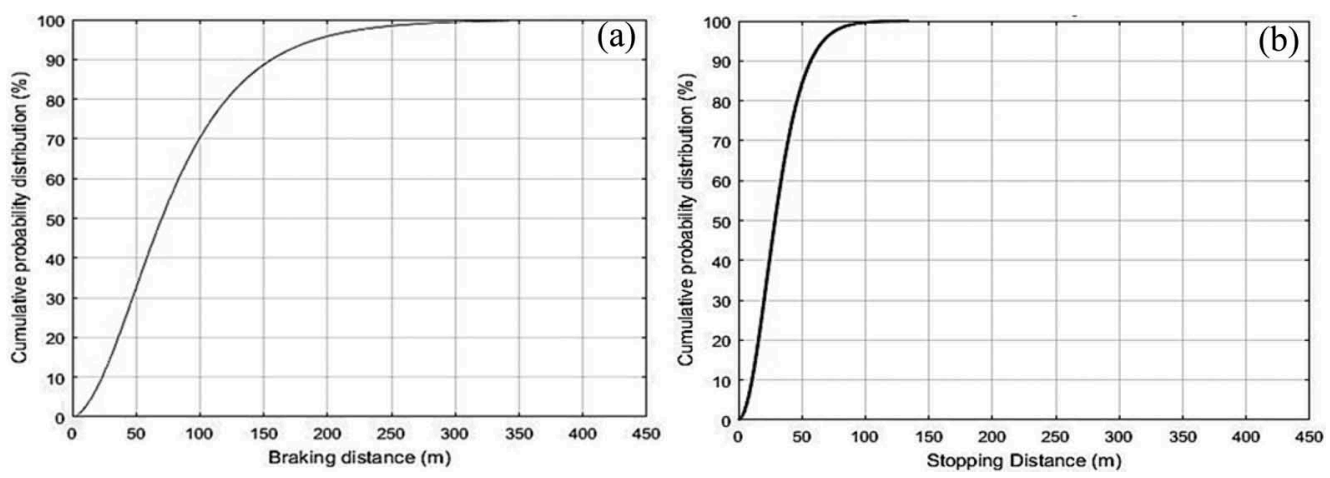

Figure 3. Primary output; Cumulative aircraft arresting distance PDF of B747-8 in case of landing overrun, (a) for paved RESA, (b) for RESA enhanced with EMAS.

Probabilistic contour intervals of aircraft arresting distances, as the secondary output, is basically a representation of the spatial probability distribution of aircraft arresting distances within the EMAS layout or within the paved RESA area, that is plotted at the end of understudy runway (Figures 4 and 5).

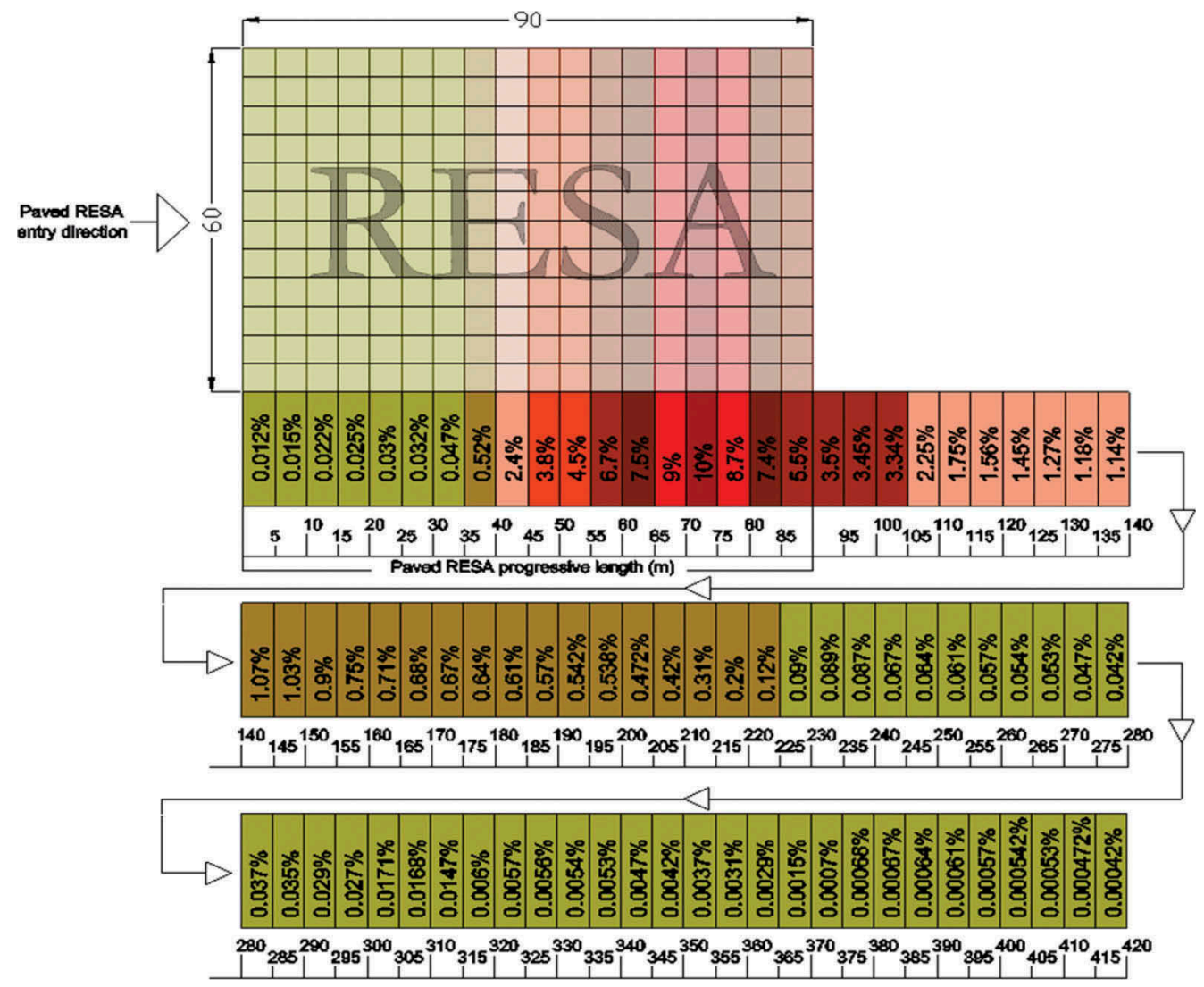

Figure 4. Secondary output; Probabilistic contour intervals for B747-8 arresting distances in case of Paved RESA. 
Figures 4 and 5 determine critical locations on paved RESA and on EMAS geometry (in case of RESA enhanced with EMAS) with higher probabilities of aircraft reaching the full stop. In the calculation of paved RESA without EMAS installation, the length and the width of the RESA are considered $90 \mathrm{~m}$ and $60 \mathrm{~m}$ respectively. The reason of selecting a RESA with mentioned dimension is to evaluate how effective it would be in decreasing the probability of aircraft accident in case of landing overrun. There are numerous airports with their runways surrounded with catastrophic obstacles such as residential area, mountains, sea, etc.

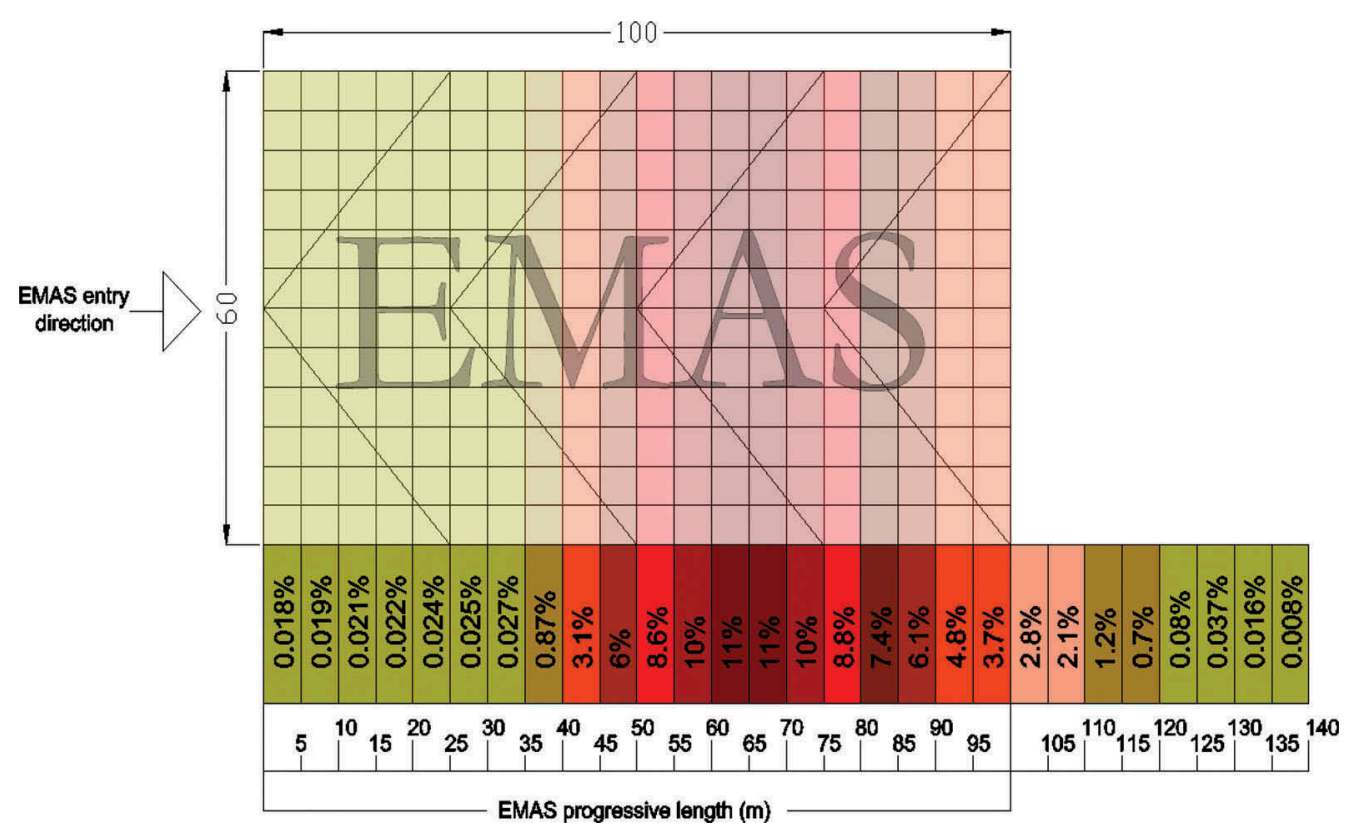

Figure 5. Secondary output; Probabilistic contour intervals for B747-8 arresting distances in case of RESA enhanced with EMAS.

An EMAS is positioned within the RESA. It is positioned within the Runway Safety Area (RSA), sets back from the runway threshold and this setback length protects the bed from aircraft intrusion during an under shoot, EMAS entry during a low velocity overrun and material degradation due to jet blast. Upon the available area at the RESA and the selected material of the EMAS this setback distance may be vary. Therefore, to plot the results, stopping distance zero is related to the starting point of aircraft entering the EMAS materials. Since deceleration rate is directly proportional to the velocity of the aircraft, where velocity decreases the deceleration rate is also decreases.

According to Figure 5, the average probabilities of arresting distances (in term of percentage) are higher in the middle of the EMAS installation. The probability that the B747-8 overruns the total EMAS area is approximately $7 \%$ beyond $100 \mathrm{~m}$, which means in $93 \%$ of the landing overrun events, EMAS can arrest an overrunning B747-8 within its area without any catastrophic consequences.

The width of the EMAS is necessary since it should cover the longest Outer Main Gear Wheel Span (OMGWS) of the critical aircraft. Moreover, solver parameters (e.g. discretization of time, probability bar interval and the properties of touchdown normal PDF) are required to be considered in the numerical computation. 


\section{FUNCTIONALITY ASSESSMENT FOR DIFFERENT EMAS MATERIALS}

Aircraft behaviors within LDC EMAS containing natural, mineral and synthetic additives with different levels crushing stress levels, are investigated by ABIAS application in order to determine a material with better functionality to be used in pre-cast blocks.

These materials consist of three LDCs with maximum crushing stress levels $\left(\mathrm{P}_{\mathrm{C}}\right)$ of 172500 , 345000 and $930000 \mathrm{~Pa}$. Low crushing stress level causes low durability for the concrete which can be an issue in maintenance of EMAS infrastructure. Selection of LDCs with various crushing stress levels does not confirm that they are economical materials to be adopted for EMAS since this statement needs corresponding cost-benefit analysis. Therefore, these LDCs are adopted in order to study the behavior of EMAS materials with lowest, medium and highest crushing strengths.

Figure 6 presents typical low-density crushable concrete behavior. The concrete exhibits a strain increase as stress increases. Beyond yielding, the material exhibits a large strain increase at a nominally constant stress (within 0.2 to 0.5 strain range). Beyond 0.5 strain, additional stress is required to develop larger strains. As the material approaches a fully crushed state ( 0.8 strain), a substantial stress increase is required to develop marginal strain increases.

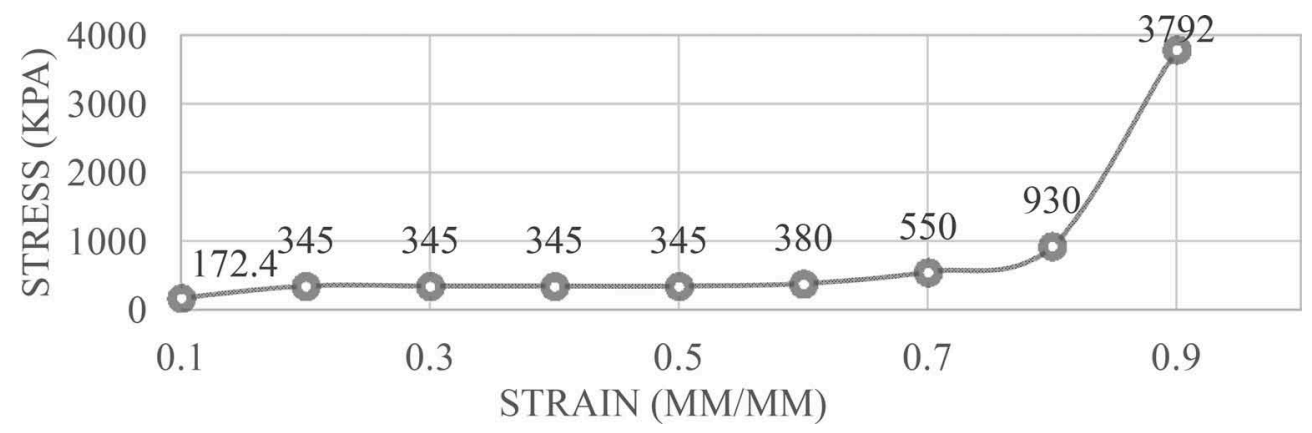

Figure 6. Low-density concrete stress/strain relationship (Heymsfield and Halsey, 2008).

The same Boeing 747-8 aircraft for the sensitivity analysis of EMAS materials is selected. The behavior of this aircraft after entering the EMAS is investigated for different arrestor bed materials with their specific crushing strengths. As presented in Figure 6, within LDCs, the strain increases initially respect to low variation in the stress values but after the material yield stress, there is a significant increase in stress but limited in strain values.

The drag force induced by the material has a correlation with the material's crushing strength and its mass density. The greater crushing strength material manages to exert, the greater drag force against the landing main gear will be generated, consequently aircraft reach to a full stop at a shorter distance, as presented in Table 1 .

Table 1. Low-density concretes to be used in arresting bed with their properties.

\begin{tabular}{llllll}
\hline No. & Arrestor materials & $\begin{array}{l}\text { Mass density } \\
{\left[\mathrm{kg} / \mathrm{m}^{3}\right]}\end{array}$ & $\begin{array}{l}\text { Crushing stress } \\
{\left[\mathrm{N} / \mathrm{m}^{2}\right]}\end{array}$ & $\begin{array}{l}\text { Arresting } \\
\text { distance }[\mathrm{m}]\end{array}$ & $\begin{array}{l}\text { Maximum drag } \\
\text { force }[\mathrm{N}]\end{array}$ \\
\hline 1 & $\begin{array}{l}\text { Low-density concrete } \\
\text { (type A) }\end{array}$ & 2300 & 175000 & 144.6 & 87800 \\
2 & $\begin{array}{l}\text { Low-density concrete } \\
\text { (type B) }\end{array}$ & 2300 & 345000 & 139.7 & 92300 \\
$\begin{array}{l}\text { Low-density concrete } \\
\text { (type C) }\end{array}$ & 2300 & 930000 & 135.5 & 116750 \\
\hline
\end{tabular}


It can be observed from Figure 7 that among the LDC mixes, there is a decrease in the aircraft arresting distance by increasing the crushing stress of the material that is used in EMAS. The arresting distance for the LDC with maximum crushing stress levels $\left(\mathrm{P}_{\mathrm{C}}\right)$ of 172500 is the longest among the others since lower drag force is generated at the tire-material interface. Therefore, the aircraft travels a longer distance before coming to a full stop.

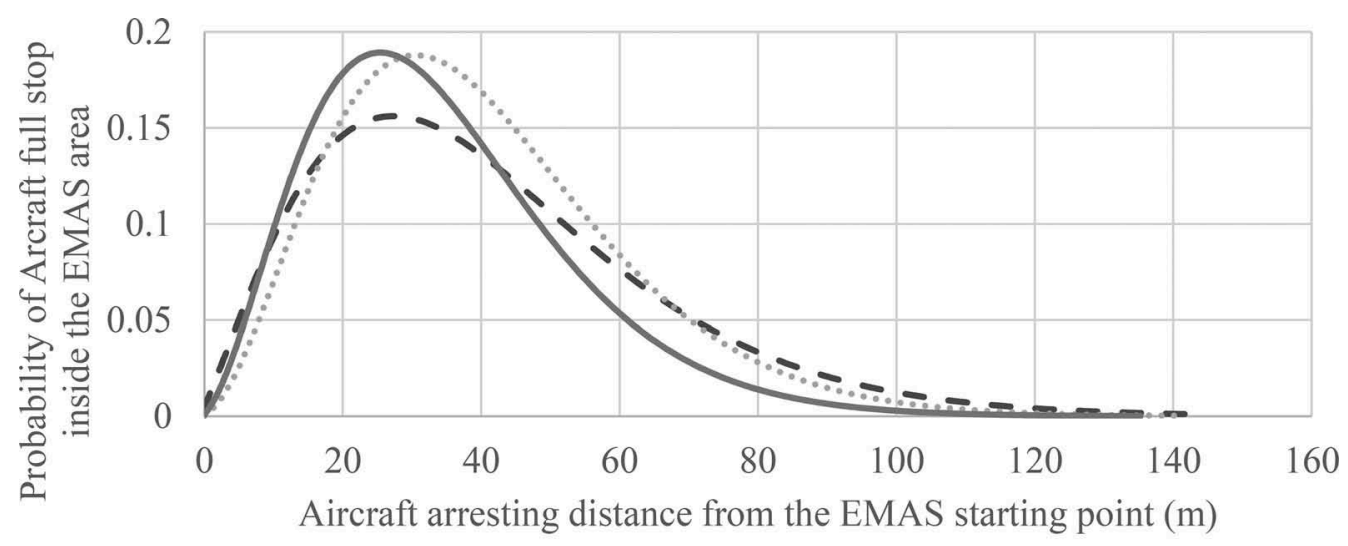

$$
\text { - - I.DC-172000 Pa …. I.DC-345000 Pa I.DC-930000 Pa }
$$

Figure 7. B747-8 arresting distance PDF in materials with different crushing stress levels.

It can be interpreted from the results that LDC with higher crushing stress level can arrest an overrunning aircraft in shorter distance since it generates higher deceleration rate respect to others.

\section{CONCLUSION}

An application named ABIAS (Aircraft Behavior in Arresting System) was developed by the authors in the platform of MATLAB ${ }^{\circledR}$ in order to simulate the behavior of aircraft within engineered material arresting system. Thanks to this application it is possible to compute the stopping distance of an aircraft within different EMAS materials. ABIAS is principally applicable for those airports with land restrictions.

Moreover, aircraft behavior is analyzed for materials with different crushing stress levels to be used in EMAS. Outputs of the calculations are plotted as arresting distances contour intervals, alongside the arrestor bed configuration $(100 \times 60 \mathrm{~m})$ for low-density concrete mixes with crushing stress levels of 172500 (type A), 345000 (type B) and 930000 Pa (type C).

Aircraft arresting distance within the EMAS area decreases when the crushing strength of the material increases. Arresting bed formed by LDC type A causes the longest aircraft stopping distance because of its lower drag force that can generate respect to others. Drag force has a direct correlation with the material's crushing strength and mass density. Materials with greater crushing strengths cause greater drag forces against the landing gear, therefore, aircraft reaches to a full stop at a shorter distance.

To conclude, an EMAS is proposed to be considered as the most rational and feasible alternative solution for land-locked airport in order to respect the FAA and ICAO RESA recommendations and to mitigate the consequences of landing overrun events. 


\section{REFERENCES}

Cook, R. F., 1985. Aircraft operation on soil prediction techniques. Technical Report ESL-84-04, Vol. 1 and 2, U.S. Air Force Engineering and Services Centre, Tyndall Air Force Base, FL.

Cook, R. F., 1987. Soft-Ground Aircraft Arresting Systems. UNIVERSAL ENERGY SYSTEMS INC DAYTON OH.

Crispino, M., Toraldo, E. and Giustozzi, F., 2018. Improving Runway Strip Performance to Fulfill International Requirements Through Eco-Efficient Soil Treatments: Case Study of a Major Italian Airport. Environmental Engineering \& Management Journal (EEMJ), 17 (6).

European Aviation Safety Agency, 2014. Final report. Study on models and methodology for safety assessment of Runway End Safety Areas.

FAA, 2004. Order 5200.9. Financial Feasibility and equivalency of Runway Safety Area Improvements and Engineered Material Arresting Systems.

FAA, 2005. Advisory Circular 150/5220-22A. Engineered Materials Arresting Systems (EMAS) for Aircraft Overruns.

Heymsfield, E. and Halsey, T. L., 2008. Sensitivity analysis of engineered material arrestor systems to aircraft and arrestor material characteristics. Transportation Research Record, 2052(1), pp 110-117.

Heymsfield, E., 2009. Performance Prediction of Strong Company's Soft Ground Arrestor System using a Numerical Analysis. Arkansas, USA, Mack Blackwell Transportation Center.

Heymsfield, E., 2013. Predicting aircraft stopping distances within an EMAS. Journal of Transportation Engineering, 139(12), pp 1184-1193.

Heymsfield, E., 2016. Jet Stopping Distance and Behaviour in a Regional Airport EMAS. Journal of Performance of Constructed Facilities 30.5: 04016010.

International Civil Aviation Administration, 2010. ICAO Annex 6 - Part 1. Operation of Aircraft - International Commercial Air Transport - Aeroplanes.

Ketabdari, M., Giustozzi, F. and Crispino, M., 2018. Sensitivity analysis of influencing factors in probabilistic risk assessment for airports. Safety science, 107, pp 173-187. http://dx.doi.org/10.1016/j. ssci.2017.07.005

Ketabdari, M., Crispino, M. and Giustozzi, F., 2019. Probability contour map of landing overrun based on aircraft braking distance computation. Pavement and Asset Management, CRC Press, pp. 731-740. http://dx.doi.org/10.1201/9780429264702

Ketabdari, M., Toraldo, E. and Crispino, M., 2020. Numerical Risk Analyses of the Impact of Meteorological Conditions on Probability of Airport Runway Excursion Accidents. In International Conference on Computational Science and Its Applications (pp. 177-190). Springer, Cham. https://doi.org/ 10.1007/978-3-030-58799-4_13

Pasindu, H. R., Fwa, T. F. and Ghim P. O., 2011. Computation of aircraft braking distances. Transportation research record 2214.1, 126-135. 